\title{
Electron-Transfer Dissociation
}

National Cancer Institute

\section{Source}

National Cancer Institute. Electron-Transfer Dissociation. NCI Thesaurus. Code C161781.

A method to induce ion fragmentation of large cationic molecules through the transfer of negatively charged electrons. 